\title{
Influence of addition of silanized nanosilica and glycerol on hydrophobicity of starch using a factorial design
}

\author{
Fernando Luis Panin Lopes ${ }^{1}$, Vicente Lira Kupfer², Júlio César Dainezi de Oliveira1', Eduardo Radovanovic², \\ Andrelson Wellington Rinaldi², Murilo Pereira Moisés ${ }^{3}$ and Silvia Luciana Favaro ${ }^{1 *}$ \\ 'Departament of Mechanical Engineering, Maringá State University - UEM, Maringá, PR, Brazil \\ ${ }^{2}$ Departament of Chemistry, Maringá State University - UEM, Maringá, PR, Brazil \\ ${ }^{3}$ Paraná Federal Technological University - UTFPR, Apucarana, PR, Brazil \\ *sIfavaro@hotmail.com
}

\begin{abstract}
The thermoplastic starch (TPS) is regarded as a promising material for manufacturing packaging and products with biodegradable properties. This study aimed at obtaining hydrophobic starch using silanized silica nanoparticles (nSS) with hexamethyldisilazane. A factorial design $2^{2}$ with central point was developed to evaluate the influence of glycerol (plasticizer) and nSS addition on the properties of water absorption, solubility and TPS contact angle. The materials morphology was also evaluated by means of scanning electron microscopy. The amount of glycerol and nSS influenced on starch hydrophobic character, for the increase of the glycerol dosage contributed to the increase of absorption and solubility of TPS in water. On the other hand, nSS has greater influence on the characteristics related to the TPS surface, favoring an increase of up to $27 \%$ in the contact angle values. Therefore, the sample with the greatest hydrophobic character was obtained by using lowest amounts of glycerol (30\%) and highest amounts of nSS (5\%).
\end{abstract}

Keywords: biodegradable polymer, thermoplastic starch, silanized nanosilica.

\section{Introduction}

The search for new polymeric materials, mainly the ones that derivate from renewable sources, has been the reason for the realization of diverse studies ${ }^{[1-4]}$. A material with promising potential for that end is the starch, for its raw material is very accessible in many parts of the world. Besides that, in general, it is obtained with low costs, being used at the formation of blends or composites with polymeric materials ${ }^{[1-6]}$.

Starch can be obtained from different vegetable sources, such as rice, maize, potatoes and cassava. These are the most important sources of that carbohydrate ${ }^{[7]}$. Among the mentioned sources, the cassava starch can be highlighted for the production of thermoplastic starch (TPS), for presenting mechanical, chemical and physical properties that are interesting from the processing and application point of view ${ }^{[8]}$. Because of these characteristics, cassava starch has been studied by many Brazilian researchers, aiming at producing biodegradable plastics ${ }^{[9-11]}$.

In the process of making biodegradable plastics with starch, it is necessary to add a plasticizer, once starch presents a degradation temperature lower than its fusion point. The most commonly used plasticizers are water and glycerol ${ }^{[11,12]}$. Besides that, compatibilizing agents, such as block or grafted copolymers can be used. These agents cause the material tenacity to change in relation to the thermoplastic, because they make the size of the disperse phase decrease $\mathrm{e}^{[13]}$.

The thermoplastic starch has good characteristics for the oxygen barrier. Nevertheless, many limitations are noticed in relation to its hydrophilic characteristics and permeability

to water vapor, which are responsible for the deterioration of mechanical properties and for dimensional stability ${ }^{[8-10,14-18]}$.

This way, aiming at the improvement of the thermoplastic starch (TPS) properties, we have used, in this work, silanized silica nanoparticles. It consists of high-purity silica, treated with hexamethyldisilazane. This treatment aimed to substitute hydroxyl groups of the pyrogenic silica with trimethylsilyl groups, which makes silica extremely hydrophobic. The silanized silica nanoparticles have been used in stickers, sealants, paints, toners and for making products for skin and beauty care ${ }^{[19]}$. The aim of this work was obtaining a biodegradable and hydrophobic starch-based polymer. The addition of glycerol and of silica hydrophobic nanoparticles was evaluated for the solubility, absorption and contact angle of the polymer produced, using factorial design.

\section{Materials and Methods}

The materials used in this study were: cassava starch, donated by INPAL S.A. Indústria Química (a Chemical Factory), located in the region of São Tomé - Paraná, Brazil; Glycerol (Nuclear, 98\%) and CAB-O-SIL ${ }^{\circledR}$ silanized silica nanoparticles (nSS) TS-530 (99.8\% $\left.\mathrm{SiO}_{2}\right)$.

The biodegradable polymers with hydrophobic characteristics were obtained from the grinding of in natura cassava starch, with different ratios of glycerol and silanized silica nanoparticles (nSS), which was later processed by extrusion, in a twin-screw extruder MiniLab II HAAKE Rheomex CTW 5. The extrusion speed was kept between 50 and $100 \mathrm{rpm}$, at a temperature of $140{ }^{\circ} \mathrm{C}$. 
In order to evaluate the influence and the interaction of nSS and glycerol for obtaining starch with hydrophobic characteristics, was done a study of a complete factorial design $2^{2}$ complete with central point. The statistical data were analyzed by using a computer program, Design-Expert ${ }^{\circledR}$. Table 1 presents the inferior $(-1)$ and superior $(+1)$ levels and the central points $(0)$ of the variables $\operatorname{nSS}(\mathrm{A})$ and glycerol (B). All the experiments were performed in duplicate and at random, which generated 12 experiments in total, as shown in Table 2. In that Table the name of each sample and the conditions used at each experiment are also mentioned. The samples identification follows this order: TPS, glycerol percentage/silica percentage, number of the replication. For instance, sample TPS_30G/1Si02 was prepared with $30 \%$ of glycerol, $1 \%$ of silica, and is a duplicate of sample TPS_30G/1Si 01.

\subsection{Characterization}

The silica nanoparticles were characterized by Scanning Electron Microscopic (SEM) and Transmission Electron Microscopy (TEM). The SEM was carried out by a Quanta 250 from FEI Company (Hillsboro, OR, USA) with and accelerating voltage of $5 \mathrm{kV}$. The TEM images were recorded using JEOL JEM-140 equipment operated at 120KV.

The biodegradable polymers with hydrophobic characteristics were characterized by trials of water absorption, solubility and water contact angle. The scanning electron microscopy (SEM) was employed to evaluate the dispersion of the nSS particles in the polymeric material and its morphology.

The water absorption trial was carried out for the comparison of TPS with the different percentages of glycerol and nSSin relatedto the polymer mass. Firstly, the biodegradable polymers with hydrophobic characteristics were dried, until the mass became constant, by use of a desiccator with blue silica gel (4-8mm, Synth), at room temperature. After that, they were kept in a glass jar with humidity controlled at $75 \%$ (supersaturated sodium chloride aqueous solution) at room temperature, according to the standard ASTM-E-104-85. The masses of the biodegradable polymers were analyzed chronologically, until they remained constant. This way, the quantity of water absorption was calculated by Equation 1 and by the weighing of the results of three samples of each formulation.

$$
A b_{H_{2} O}(\%)=\left(\frac{M_{U}-M_{S}}{M_{S}}\right) \times 100
$$

in which: $\mathrm{Ab}_{\mathrm{H}_{2} \mathrm{O}}$ is the water absorption of the polymer, in percentage; $M_{U}$ is the wet mass of the polymer in successive time intervals; $M_{S}$ is the dry mass of the polymer.

The analysis of solubility in water was performed in triplicate, following the method proposed by Gontard et al. ${ }^{[20]}$. The samples were dried in an oven with air circulation and renovation for a 24 -hour period, at $105^{\circ} \mathrm{C}$.After this process, the initial dry weight was obtained. The samples were immersed in $50 \mathrm{~mL}$ of distilled water, kept under slow and periodic stirring for a 48 -hour period, at $25^{\circ} \mathrm{C}$. After this period, the remaining film fragments were removed from water and dried in an oven $\left(105^{\circ} \mathrm{C}, 24\right.$ hours $)$ for determining the final dry mass. The solubility was expressed according to Equation 2, where $M_{S i}$ is the sample initial dry mass and $M_{S f}$ is the sample final dry mass:

$$
\text { Solubility }(\%)=\frac{M_{S i}-M_{S f}}{M_{S f}} \times 100
$$

For the evaluation of the contact angle, films made from pellets of the plastified starch were prepared. For obtaining the films, a heated hydraulic press was used; three samples were heated for three minutes at $140^{\circ} \mathrm{C}$ and, after that, they were submitted to the pressure of $1.10^{3} \mathrm{~kg} / \mathrm{cm}^{2}$. They were kept under that pressure condition until the polymeric film returned to room temperature. The contact angle measured with the water sessile drop method was obtained with Tantec equipment. Each value was taken as an average of five measurements in different parts of two samples produced in the same experimental conditions.

The SEM images were obtained from a microscope Shimadzu model SS 550. To this, the polymers were prepared by means of a cryogenic fracture with liquid nitrogen $\left(-196^{\circ} \mathrm{C}\right)$, placed on a specimen holder with adhesive tape, covered with a thin gold layer by sputtering, leaving the area where the fracture occurred exposed to be analyzed.

\section{Results and Discussions}

\subsection{Characterization of silica}

Figure 1 presents the images obtained from scanning electron microscopy and from transmission electron microscopy of silanized silica nanoparticles (nSS), as received. By means of the scanning electron microscopy image, it can be seen that the nSS present agglomerations of nanoparticles with sizes varying from 5 to $20 \mu \mathrm{m}$. These results were confirmed by transmission electron microscopy.

\subsection{Starch modified with silica}

The responses obtained from the trials of water absorption, solubility and contact angle were used at the experimental design $2^{2}$ with central point (Table 2). Those responses are presented in Table 3, which also contains the data for the sample without nSS (TPS 30G) addition.

The main effects of the variables silica quantity (A) and glycerol quantity (B), as well as the combination among the factors at the values of solubility, absorption and contact angle, according to the design described in Table 3, were evaluated on the software Design-Expert ${ }^{\circledR}$. With the

Table 1. Factors and levels of the factors used at the factorial design $2^{2}$ complete for hydrophobic starch.

\begin{tabular}{ccccccc}
\hline Factor & Name & Unity* & Type & Level (-1) & Level (0) & Level (+1) \\
\hline A & Silica & $\%$ & Numerical & 1.0 & 3.0 & 3.0 \\
B & Glycerol & $\%$ & Numerical & 30.0 & 35.0 & 40.0 \\
\hline
\end{tabular}

*Silica and glycerol percentage in relation to the total mass. 
application of the experimental designing, the models, represented by Equations3, 4 and 5, were obtained for water absorption, solubility and contact angle, respectively. In order to evaluate the reliability of the models proposed,

Table 2. Complete factorial design $2^{2}$, study in duplicate with central point.

\begin{tabular}{ccc}
\hline \multirow{2}{*}{ Samples } & \multicolumn{2}{c}{ Factors } \\
\cline { 2 - 3 } & A Silica [\%] & B Glycerol [\%] \\
\hline TPS_30G/1Si 01 & $(-1) 1.0$ & $(-1) 30.0$ \\
TPS_30G/1Si 02 & $(-1) 1.0$ & $(-1) 30.0$ \\
TPS_30G/5Si 01 & $(+1) 5.0$ & $(-1) 30.0$ \\
TPS_30G/5Si 02 & $(+1) 5.0$ & $(-1) 30.0$ \\
TPS_40G/1Si 01 & $(-1) 1.0$ & $(+1) 40.0$ \\
TPS_40G/1Si 02 & $(-1) 1.0$ & $(+1) 40.0$ \\
TPS_40G/5Si 01 & $(+1) 5.0$ & $(+1) 40.0$ \\
TPS_40G/5Si 02 & $(+1) 5.0$ & $(+1) 40.0$ \\
TPS_35G/3Si 01 & $(0) 3.0$ & $(0) 35.0$ \\
TPS_35G/3Si 02 & $(0) 3.0$ & $(0) 35.0$ \\
TPS_35G/3Si 03 & (0) 3.0 & $(0) 35.0$ \\
TPS_35G/3Si 04 & (0) 3.0 & (0) 35.0 \\
\hline
\end{tabular}

Table 3. Responses obtained at the experiments of the complete factorial design $2^{2}$.

\begin{tabular}{lccc}
\hline & \multicolumn{3}{c}{ RESPONSES } \\
\cline { 2 - 4 } SAMPLES & $\begin{array}{c}\text { Water } \\
\text { absorption } \\
\text { [\%] }\end{array}$ & Solubility[\%] & $\begin{array}{c}\text { Contact } \\
\text { angle } \\
\text { [degrees] }\end{array}$ \\
\hline TPS_30G & $24.1 \pm 0.1$ & $44.1 \pm 0.2$ & $61.2 \pm 0.1$ \\
TPS_30G/1Si 01 & $16.9 \pm 0.1$ & $37.7 \pm 1.5$ & $66.5 \pm 1.7$ \\
TPS_30G/1Si 02 & $16.5 \pm 0.4$ & $33.6 \pm 0.8$ & $70.0 \pm 1.0$ \\
TPS_30G/5Si 01 & $17.0 \pm 0.1$ & $31.2 \pm 0.7$ & $91.8 \pm 1.6$ \\
TPS_30G/5Si 02 & $17.0 \pm 0.4$ & $29.7 \pm 0.7$ & $83.6 \pm 2.4$ \\
TPS_40G/1Si 01 & $19.8 \pm 0.1$ & $45.0 \pm 0.3$ & $85.4 \pm 1.0$ \\
TPS_40G/1Si 02 & $20.0 \pm 0.1$ & $40.7 \pm 0.8$ & $80.0 \pm 2.0$ \\
TPS_40G/5Si 01 & $19.5 \pm 0.1$ & $42.8 \pm 1.5$ & $89.1 \pm 2.0$ \\
TPS_40G/5Si 02 & $19.1 \pm 0.1$ & $36.2 \pm 0.5$ & $87.3 \pm 1.0$ \\
TPS_35G/3Si 01 & $18.5 \pm 0.1$ & $35.3 \pm 0.7$ & $72.5 \pm 2.3$ \\
TPS_35G/3Si 02 & $17.4 \pm 0.2$ & $38.0 \pm 0.4$ & $83.7 \pm 1.6$ \\
TPS_35G/3Si 03 & $18.5 \pm 0.1$ & $38.1 \pm 2.2$ & $81.2 \pm 2.2$ \\
TPS_35G/3Si 04 & $18.3 \pm 0.1$ & $30.2 \pm 1.9$ & $77.5 \pm 2.5$ \\
\hline
\end{tabular}

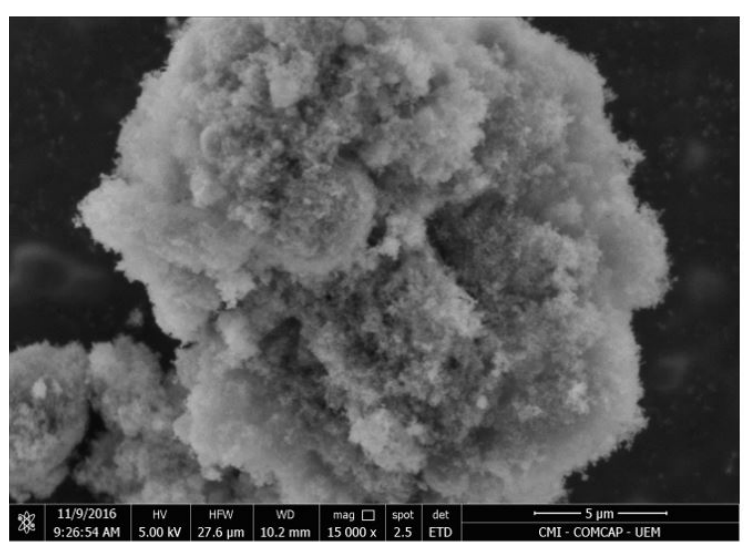

the analysis of variance (ANOVA)was used. From ANOVA, it could be observed that all the models (Tables 4, 5 and 6) fit well to the experimental data, without presenting any significant lack of fit.

$$
\begin{aligned}
& \text { Water absorption }=+6.35-0.75 \times \text { Silica }+ \\
& 0.34 \times \text { Glycerol }+0.02 \times \text { Silica } \times \text { Glycerol } \\
& \text { Solubility }=+16.77-2.71 \times \text { Silica }+\mathrm{x} \\
& \text { Glycerol }+0.04 \times \text { Silica } \times \text { Glycerol } \\
& \text { Contact Angle }=+9.57+15.32 \times \text { Silica }+ \\
& 1.79 \times \text { Glycerol }-0.35 \times \text { Silica } \times \text { Glycerol }
\end{aligned}
$$

By means of the analysis of variance of the factorial $2^{2}$ for the data of water absorption trial presented in Table 4, it can be observed that variable B - quantity of glycerol - showed to be statistically significant ( $p$-value $<0.05$ ). Therefore, as the quantity of glycerol used for the starch plastification increases, the quantity of water absorbed also raises. On the other hand, variable A (quantity of nSS) and the interaction between the factors $\mathrm{AB}$ are not statistically significant for the model, because, by test F, they present a value $\mathrm{p}$ much higher than 0.05 . In Figure 2, the response surface obtained for the model is presented. A significant increase in water absorption with the addition of glycerol percentage can be confirmed.

Farahnaky et al. ${ }^{[21]}$ performed a study with edible polymeric films of native starch by varying the amount of glycerol. They observed that in high moisture environment up to $84 \%$, those polymeric films have mass gain increase until $54 \%$.

In a study carried out by Plotegher and Ribeiro ${ }^{[22]}$ with TPS reinforced withZSM-5 Zeolite and colloidal silica, it could be observed that the introduction of both fillers reduced the permeability to water vapor in up to $20 \%$ when compared to the permeability of pure TPS. There are other studies that mention the use of TPS and paraffin; they show that the addition of paraffin in all the formulations reduces the water absorption ${ }^{[23]}$.

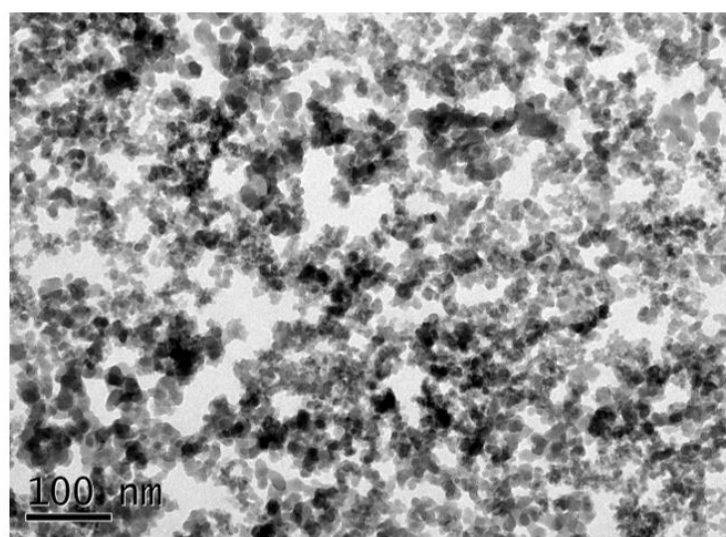

Figure 1. Scanning electron microscopy (left) and transmission electron microscopy (right) of silanized silica nanoparticles (nSS) TS-530 $\left(\mathrm{SiO}_{2}\right)$ from CAB-O-SIL ${ }^{\circledR}$. 
Table 4. ANOVA obtained for the design of Table 3 with an adjustment for the data obtained in the water absorption trial.

\begin{tabular}{lcccrc}
\hline Water absorption & Sum of squares & Freedom degree & Average of squares & Value F & Value P \\
\hline Model & 15.57 & 3 & 5.19 & 36.07 & 0.0001 \\
A (Silica) & 0.045 & 1 & 0.045 & 0.31 & 0.5935 \\
B (Glycerol) & 15.12 & 1 & 15.12 & 105.09 & $<0.0001$ \\
AB & 0.40 & 1 & 0.40 & & 0.1374 \\
Pure Error & 1.01 & 7 & 0.14 & \\
Total & 16.59 & 11 & & & \\
\hline
\end{tabular}

$\mathrm{R}^{2}=0.9212$ (percentage of prediction of model $=92.12 \%$ ).

Table 5. ANOVA obtained from the central composite design of Table 3 with an adjustment for the solubility trial.

\begin{tabular}{lccccc}
\hline \multicolumn{1}{c}{ Solubility } & Sum of squares & Freedom degree & Average of squares & Value $\mathbf{F}$ & Value $\mathbf{P}$ \\
\hline Model & 170.47 & 3 & 56.82 & 4.86 & 0.0391 \\
A (Silica) & 36.42 & 1 & 36.42 & 3.11 & 0.1210 \\
$B$ (Glycerol) & 132.28 & 1 & 132.28 & 11.31 & 0.0120 \\
AB & 1.78 & 1 & 1.78 & 0.15 & 0.7083 \\
Pure Error & 81.89 & 7 & 11.70 & 0.66 & \\
Total & 260.03 & 11 & & & \\
\hline
\end{tabular}

$\mathrm{R} 2=0.6556$ (percentage of prediction of model $=65.56 \%$ ).

Table 6. ANOVA obtained for the design of Table 3, with an adjustment for the results of contact angle.

\begin{tabular}{lccccc}
\hline \multicolumn{1}{c}{ Contact Angle } & Sum of squares & Freedom degree & Average of squares & Value F & Value P \\
\hline Model & 520.30 & 3 & 173.43 & 9.55 & 0.0072 \\
$A$ (Silica) & 311.25 & 1 & 311.25 & 17.15 & 0.0043 \\
$B$ (Glycerol) & 111.75 & 1 & 111.75 & 6.16 & 0.0421 \\
AB & 97.30 & 1 & 97.30 & 5.36 & 0.0538 \\
Pure Error & 127.07 & 7 & & & \\
Total & 671.18 & 11 & & & \\
\hline
\end{tabular}

$\mathrm{R}^{2}=0.7752$ (percentage of prediction of model $=77.52 \%$ ).

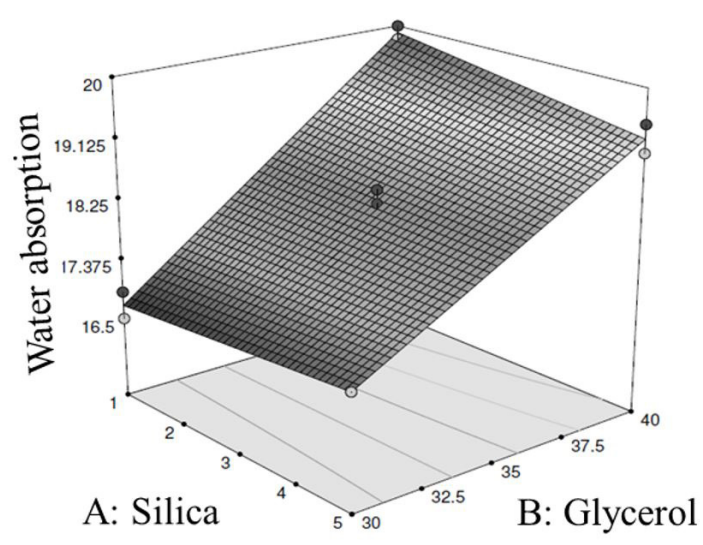

Figure 2. Response surface obtained at factorial $2^{2}$ presented in Table 4.

Table 5 presents the analysis of factorial variance $2^{2}$ for the solubility trial. It can be observed that variable A and the interaction between factors $\mathrm{AB}$ do not present a significant level for the model ( $p$-value $>0.05$ ). In its turn, variable B is statistically significant. Figure 3 presents the obtained response surface. A significant increase of the starch solubility with the addition of glycerol percentage cane noticed.

In a study carried out by Matta et al. ${ }^{[24]}$ for analyzing the solubility of biofilms obtained from peas starch with xanthan

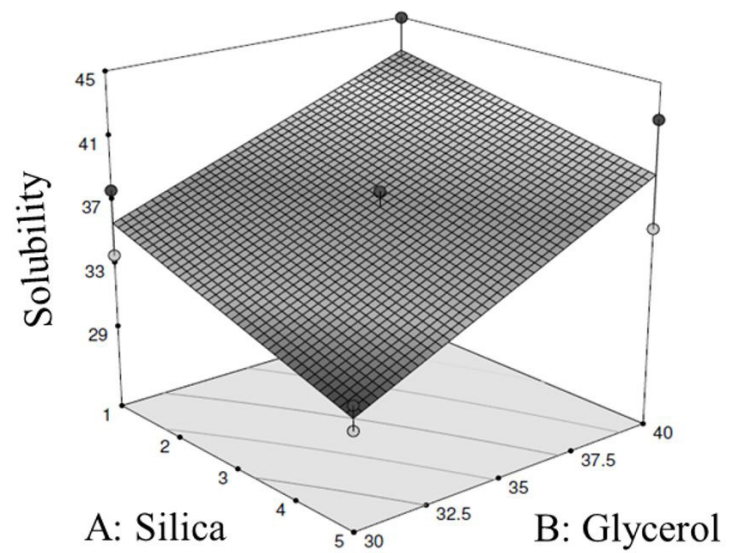

Figure 3. Response surface obtained at factorial $2^{2}$ presented in Table 5.

gum and glycerol, one could observe that the addition of glycerol increased the film solubility. It occurred because glycerol interacts with the film matrix, increasing the free space between the chains; it facilitates the entrance of water, thus increasing the solubility ${ }^{[24-27]}$.

The analysis of variance of factorial $2^{2}$ generated from the data of the contact angle trial (Table 6) presents significant statistics, for $\mathrm{nSS}$ (variable A) as well as for glycerol (variable B). However, it can be observed that the quantity of nSS had high influence to the model, because, 


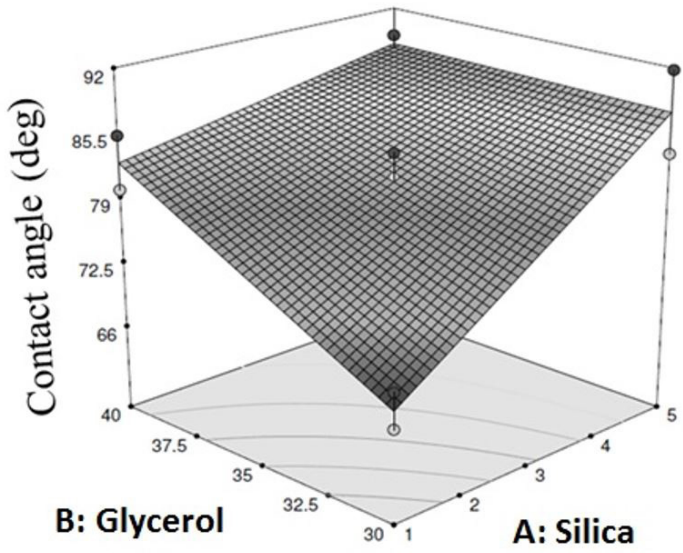

Figure 4. Response surface obtained at factorial $2^{2}$ presented in Table 6. by test F, a p-value much lower than 0.05 can be noticed. On the response surface illustrated in Figure 4, it can be observed that highest values of contact angles are obtained with around $5 \%$ of nSS. This fact can be related to the presence of nonpolar group in nSS on the TPS surface. It causes an increase in the contact angle ${ }^{[28,29]}$ and a change of its hydrophobic characteristics.

The highest contact angle obtained was $91.8^{\circ}$ for the sample TPS $30 \mathrm{G} / 5 \mathrm{Si}$, a value $33.3 \%$ higher when compared to the TPS without addition of nSS with $30 \%$ of glycerol $\left(61.2^{\circ}\right)$. This trend is noticed in polymers based on starch as well. The raising of glycerol content increases the hydrophilicity of these films, which might be related with the $\mathrm{OH}$ functional groups of the glycerol ${ }^{[30-33]}$.

Figure 5 presents the images of scanning electron microscopy of the polymers with hydrophobic characteristics on the fracture surface of the TPS samples, according to

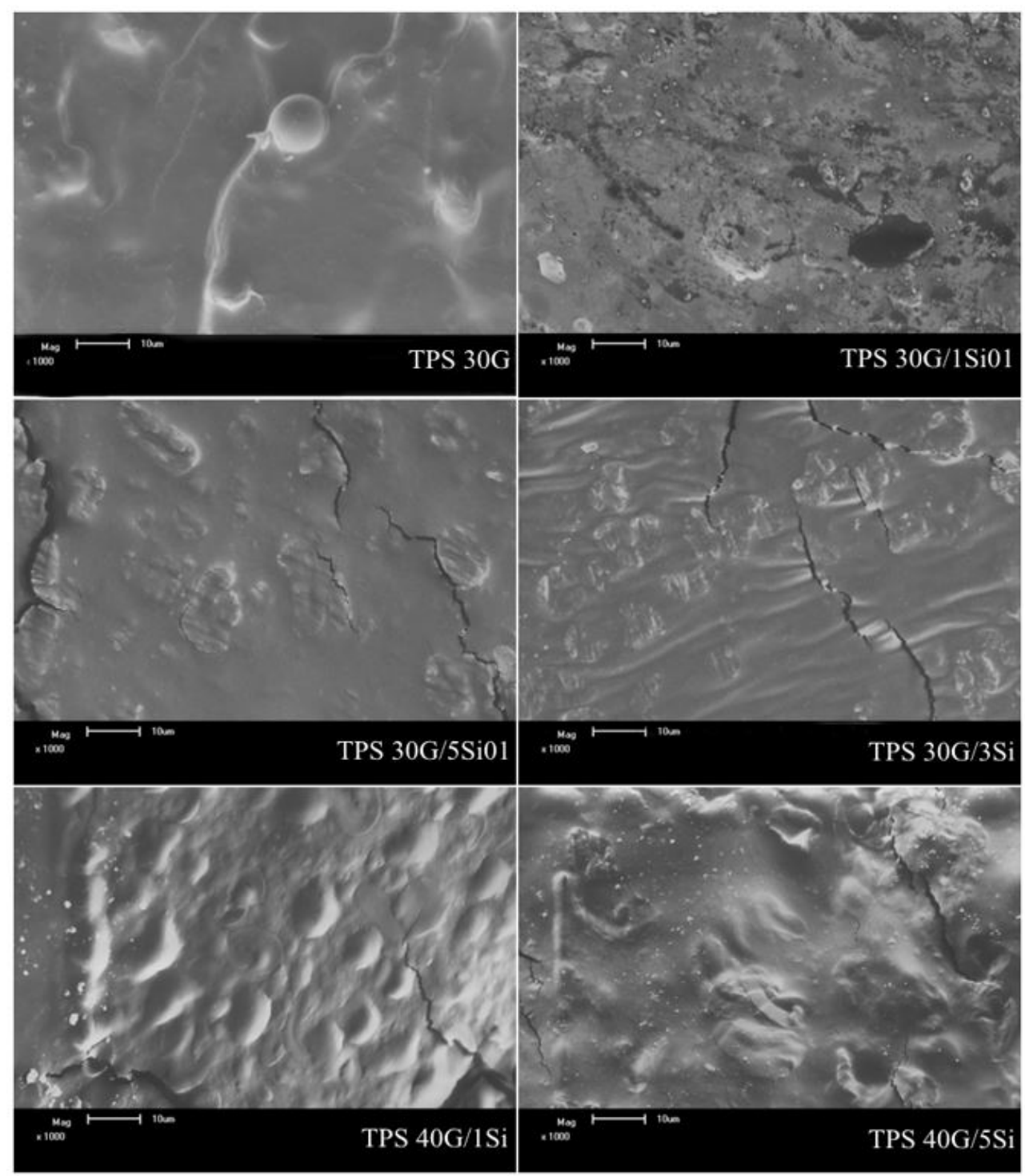

Figure 5. Scanning electron microscopies for the TPS_30G and other formulations generated by the factorial study, according to Table 2. 
the nomenclature presented in Table 2. It can be observed that both polymeric materials present similar morphology, and from the cryogenic fractures, the presence of nSS nanoparticles is seen. Furthermore, it could also be observed that the nSS nanoparticles showed a very close similarity in their homogeneities comparing all percentages of polymeric materials used.

The results obtained in the factorial design can be better understood with the analysis of the morphology of the samples.

The formulations of TPS and nSS, in general, present a homogeneous appearance and a good dissolution of the starch granules after the plastification process. In Figure 5, we highlight the fact that the samples TPS_30G/1Si 01 and TPS_40G/5Si 01 present a better dispersion of nSS in the polymeric matrix. Those results can be justified: the sample TPS_30G/01Si 01 has obtained the best result in the water absorption trial (16.9\%), while the sample TPS_40G/05Si 01 has obtained a high value of contact angle. The other samples presented some areas with nSS agglomerates in the TPS matrix, which can be associated to the extrusion process.

\section{Conclusion}

From the complete factorial design 22 with central point, we could evaluate that both factors, quantity of glycerol and silanized nanosilica, influence on the process to obtain starch with hydrophobic characteristics; glycerol has a higher influence on the characteristics related to the polymer bulk, presenting higher water absorption and higher solubility with the increase of the plasticizer glycerol. On the other hand, the quantity of silanized nanosilica has more influence on the characteristics related to the surface. Therefore, there is a significant increase in the values of contact angle with addition of $5 \%$ of silanized nanosilica.

The material developed in this study has a high potential to be applied in the preparation of blends with synthetic and hydrophobic polymers, such as polyethylene and polypropylene.

\section{Acknowledgements}

We gratefully acknowledge the Brazilian agencies (CAPES/ CNPQ) for the financial support. We would like to acknowledge to COMCAP/UEM for the electron microscopy analysis.

\section{References}

1. Avérous, L. (2004). Biodegradable multiphase systems based on plasticized starch: a review. Journal of Macromolecular Science-Polymer, 44(3), 231-274. http://dx.doi.org/10.1081/ MC-200029326.

2. Corradini, E., Medeiros, E. S., Carvalho, A. J. F., Curvelo, A. A. S., \& Mattoso, L. H. C. (2006). Mechanical and morphological characterization of starch/zein blends plasticized with glycerol. Journal of Applied Polymer Science, 101(6), 4133-4139. http:// dx.doi.org/10.1002/app.23570.

3. Leng, Y., Zhang, Y., Chen, X., Yi, C., Fan, B., \& Wu, Q. (2011). Hydrophobic thermoplastic starches modified with polyester-based polyurethane microparticles: effects of various diisocyanates. Industrial \& Engineering Chemistry Research, 50(19), 11130-11135. http://dx.doi.org/10.1021/ie201133z.
4. Ning, W., Jiugao, Y., Xiaofei, M., \& Ying, W. (2007). The influence of citric acid on the properties of thermoplastic starch/ linear low-density polyethylene blends. Carbohydrate Polymers, 67(3), 446-453. http://dx.doi.org/10.1016/j.carbpol.2006.06.014.

5. Ghavimi, A. A. S., Ebrahimzadeh, M. H., Solati-Hashjinand, M., \& Osman, A. A. N. (2015). Polycaprolactone/starch composite: fabrication, structure, properties and applications. Journal of Biomedical Materials Research. Part A, 103(7), 2482-2498. PMid:25407786. http://dx.doi.org/10.1002/jbm.a.35371.

6. Cano, A., Fortunati, E., Cháfer, M., González-Martínez, C., Chiralt, A., \& Kenny, J. M. (2015). Effect of cellulose nanocrystals on the properties of pea starch-poly(vinyl alcohol) blend films. Journal of Materials Science, 50(21), 6979-6992. http://dx.doi.org/10.1007/s10853-015-9249-9.

7. Bobbio, F. O., \& Bobbio, P. A. (1995). Introdução à química de alimentos. São Paulo: Livraria Varela.

8. Melo, C., Garcia, S. P., Grossmann, E. V. M., Yamashita, F., Dall'Antônia, H. L., \& Mali, S. (2011). Properties of extruded xanthan-starch-clay nanocomposite films. Brazilian Archives of Biology and Technology, 54(6), 1223-1333. http://dx.doi. org/10.1590/S1516-89132011000600019.

9. Mali, S., Grossmann, M. V. E., \& Yamashita, F. (2010). Filmes de amido: produção propriedades e potencial de utilização. Semina. Ciências Agrárias, 31(1), 137-156. http://dx.doi. org/10.5433/1679-0359.2010v31n1p137.

10. Pellicano, M., Pachekoski, W., \& Agnelli, J. A. M. (2009). Influência da adição de amido de mandioca na biodegradação da blenda polimérica PHBV/Ecoflex ${ }^{\circledR}$. Polimeros: Ciência e Tecnologia, 19(3), 212-217. http://dx.doi.org/10.1590/S010414282009000300009.

11. Henrique, C. M., Cereda, M. P., \& Sarmento, S. B. S. (2008). Características físicas de filmes biodegradáveis produzidos a partir de amidos modificados de mandioca. Ciência e Tecnologia de Alimentos, 28(1), 231-240. http://dx.doi.org/10.1590/S010120612008000100033.

12. Roz, A. L., Carvalho, A. J. F., Gandini, A., \& Curvelo, A. A. S. (2006). The effect of plasticizers on thermoplastic starch compositions obtained by melt processing. Carbohydrate Polymers, 63(3), 417-424. http://dx.doi.org/10.1016/j. carbpol.2005.09.017.

13. Mathew, A. P., \& Dufresne, A. (2002). Plasticized waxy maize starch: effect of polyols and relative humidity on material properties. Biomacromolecules, 3(5), 1101-1108. PMid:12217059. http://dx.doi.org/10.1021/bm020065p.

14. Barra, G. M. O., Roeder, J., Soldi, V., Pires, A. T. N., \& Agnelli, J. A. M. (2003). Blendas de poliamida 6/elastômero: propriedades e influência da adição de agente compatibilizante. Polimeros: Ciência e Tecnologia, 13(2), 94-101. http://dx.doi. org/10.1590/S0104-14282003000200006.

15. Moriana, R., Vilaplana, F., Karlsson, S., \& Ribes-Greus, S. (2011). Improved thermo-mechanical properties by the addition of natural fibres in starch-based sustainable biocomposites. Composites Part A: Applied Science and Manufacturing, 42(1), 30-40. http://dx.doi.org/10.1016/j.compositesa.2010.10.001.

16. Richardson, P. H., Trksak, R. M., Tsai, J. J., \& Weisser, E. M. (2003). US Patent 6521088 B1. Degraded hydrophobic, particulate starches and their use in paper sizing. United States: United States Patent.

17. Taghizadeh, A., Sarazin, P., \& Favis, B. D. (2013). High molecular weight plasticizers in thermoplastic starch/polyethylene blends. Journal of Materials Science, 48(4), 1799-1811. http://dx.doi. org/10.1007/s10853-012-6943-8.

18. Mortazavi, S., Ghasemi, S., \& Oromiehie, A. (2013). Effect of phase inversion on the physical and mechanical properties of low density polyethylene/thermoplastic starch. Polymer Testing, 32(3), 482-491. http://dx.doi.org/10.1016/j. polymertesting.2013.01.004. 
19. Kim, D. Y. (2005). US Patent 2005220860-A1. Powder form aggregate, useful as multi-functional cosmetics, comprises liposome having cosmetic ingredient, solvent and liposome agent; and porous powders impregnated with jojoba oil emollient ingredient. United States: United States Patent.

20. Gontard, N., Duchez, C., Cuq, J. L., \& Guilbert, S. (1994). Edible composite films of wheat gluten and lipids - watervapor permeability and other physical-properties. International Journal of Food Science \& Technology, 29(1), 39-50. http:// dx.doi.org/10.1111/j.1365-2621.1994.tb02045.x.

21. Farahnaky, A., Saberi, B., \& Majzoobi, M. (2013). Effect of glycerol on physical and mechanical properties of wheat starch edible films. Journal of Texture Studies, 44(3), 176-186. http:// dx.doi.org/10.1111/jtxs. 12007.

22. Plotegher, F., \& Ribeiro, C. (2013). Preparação e caracterização de compósitos poliméricos baseados em amido termoplástico e materiais de alta área superficial: zeólita ZSM-5 e sílica coloidal. Polímeros: Ciência e Tecnologia, 23(2), 236-241. http://dx.doi.org/10.4322/polimeros.2013.078.

23. Pervaiz, M., Oakley, P., \& Sain, M. (2014). Development of novel wax-enabled thermoplastic starch blends and their morphological, thermal and environmental properties. International Journal of Composite Materials, 4(5), 204-212. http://dx.doi.org/10.5923/j.cmaterials.20140405.02.

24. Matta, M. D., Jr., Sarmento, S. B. S., Sarantópoulos, C. I. G. L., \& Zocchi, S. S. (2011). Propriedades de barreira e solubilidade de filmes de amido de ervilha associado com goma xantana e glicerol. Polímeros: Ciência e Tecnologia, 21(1), 67-72. http:// dx.doi.org/10.1590/S0104-14282011005000011.

25. Leyva, M. B., Chávez, P. T., Wong, B. R., Jatomea, M. P., \& Bojórquez, F. B. (2008). Physical and mechanical properties of durum wheat (triticum durum) starch films prepared with a and b type granules. Stärke, 60(10), 559-567. http://dx.doi. org/10.1002/star.200800227.

26. Laohakunjit, N., \& Noomhorm, A. (2004). Effect of plasticizer on mechanical and barrier properties of rice starch film. Stärke, 56(8), 348-356. http://dx.doi.org/10.1002/star.200300249.
27. Zhang, Y., \& Han, J. H. (2006). Mechanical and thermal characteristics of pea starch films plasticized with monosaccharides and polyols. Journal of Food Science, 71(2), E109-E118. http:// dx.doi.org/10.1111/j.1365-2621.2006.tb08891.x.

28. Garcia, M. A., Pinotti, A., \& Zaritzky, N. E. (2006). Physicochemical water vapor barrier and mechanical properties of corn starch and chitosan composite films. Stärke, 58(9), 453-463. http:// dx.doi.org/10.1002/star.200500484.

29. Thiré, R. M. S. M., Simão, R. A., \& Andrade, C. T. (2003). High resolution imaging of the microstructure of maize starch films. Carbohydrate Polymers, 54(2), 149-158. http://dx.doi. org/10.1016/S0144-8617(03)00167-X

30. Müller, C. M. O., Yamashita, F., \& Laurindo, J. B. (2008). Evaluation of the effects of glycerol and sorbitol concentration and water activity on the water barrier properties of cassava starch films through a solubility approach. Carbohydrate Polymers, 72(1), 82-87. http://dx.doi.org/10.1016/j.carbpol.2007.07.026.

31. Olivato, J. B., Grossmann, M. V. E., Yamashita, F., Eiras, D., \& Pessan, L. A. (2012). Citric acid and maleic anhydride as compatibilizers in starch/poly(butylene adipate-co-terephthalate) blends by one-step reactive extrusion. Carbohydrate Polymers, 87(4), 2614-2618. http://dx.doi.org/10.1016/j.carbpol.2011.11.035.

32. Olivato, J. B., Grossmann, M. V. E., Bilck, A. P., \& Yamashita, F. (2012). Effect of organic acids as additives on the performance of thermoplastic starch/polyester blown films. Carbohydrate Polymers, 90(1), 159-164. PMid:24751025. http://dx.doi. org/10.1016/j.carbpol.2012.05.009.

33. Nobrega, M. M., Olivato, J. B., Müller, C. M. O., \& Yamashita, F. (2012). Biodegradable starch-based films containing saturated fatty acids: thermal, infrared and Raman spectroscopic characterization. Polímeros: Ciência e Tecnologia, 22(5), 475480. http://dx.doi.org/10.1590/S0104-14282012005000068.

Received: Apr. 04, 2016

Revised: Dec. 02, 2016

Accepted: Dec. 20, 2016 